\title{
Composites Associated with Pulp- Protection Material: Color-Stability Analysis after Accelerated Artificial Aging
}

\author{
Diogo Rodrigues Cruvinela \\ Lucas da Fonseca Roberti Garciab \\ Simonides Consanic \\ Fernanda de Carvalho Panzeri Pires-de-Souzad
}

\section{ABSTRACT}

Objectives: This study assessed the color stability of two composites associated with two pulp protectors submitted to accelerated artificial aging (AAA).

Methods: 60 test specimens were made with $0.5 \mathrm{~mm}$ of protection material (calcium hydroxide - $\mathrm{CH}$ or glass ionomer cement - GIC) and $2.5 \mathrm{~mm}$ of restoration material (Concept or QuixFil) and divided into 3 groups $(n=10)$ according to the type of protection material/composite, and the control group (no protection). After polishing, color readings were obtained with a spectrophotometer (PCB 6807 Byk Gardner) before and after AAA for 384 hours, and L*, a*, and b* coordinates and total color variation $(\triangle E)$ were analyzed (2-way ANOVA, Bonferroni, $\alpha=05$ ).

Results: Composites placed on $\mathrm{CH}$ presented lower $\mathrm{L}^{*}$ levels than those on GIC, which presented higher $L^{*}$ values than the control group and lower $b^{*}$ values than those of the $\mathrm{CH}$ group. The Concept composite presented higher $\Delta \mathrm{E}$ levels for all groups, differing statistically from QuixFil, except when placed on GIC.

Conclusions: It was concluded that the protection material could affect the color stability and AAA is a factor that enhances this effect, depending on the type of composite used. (Eur J Dent 2010;4:6-11)

Key words: Color stability; Composites; Pulp protection; Accelerated artificial aging.

\footnotetext{
a Post-graduate student, Ribeirao Preto School of Dentistry, University of São Paulo, Ribeirao Preto, SP, Brazil.

b Post-graduate student, Piracicaba School of Dentistry, State University of Campinas, Piracicaba, SP, Brazil.

Professor, Piracicaba School of Dentistry, State University of Campinas, Piracicaba, SP, Brazil.

d Associate Professor, Ribeirao Preto School of Dentistry, University of São Paulo, Ribeirao Preto, SP, Brazil.
}

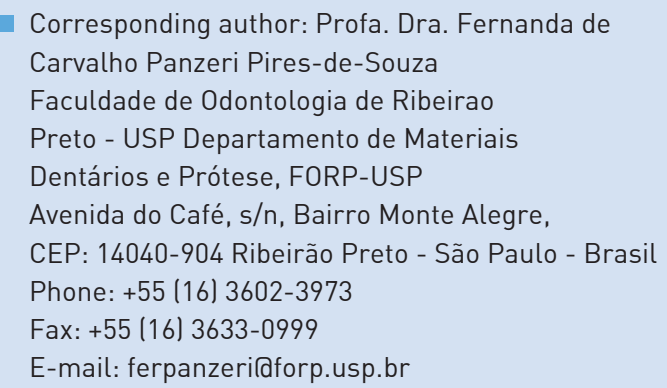




\section{INTRODUCTION}

The esthetic aspect of dental care has recently become increasingly important. There are many composites available on the market, and they are continually developed to meet the needs of professionals, who require esthetic restoration materials with simple application techniques and good mechanical and physical properties. Nevertheless, these materials are subject to frequent failures, such as marginal and/or body discoloration, in addition to micro-infiltration and porosity, ${ }^{1,2}$ which are determinant in the success of the treatment. ${ }^{3}$ Approximately 30 to $40 \%$ of the restorations made with composite resin in anterior teeth are replaced within 5 years. ${ }^{4}$ Color stability is an important property of composites used in esthetic restorations and several factors are associated with alterations of this property, such as the composition of the resin matrix and type of light curing unit used. ${ }^{5-10}$

Another important component that interferes in this property is the photo-initiator system, commonly composed of camphorquinone and aromatic or aliphatic amines that also act as accelerators. ${ }^{11}$ All amines are known to form by-products during the light-cure process, leading to discoloration of the material when under the influence of light or heat. ${ }^{12}$ Furthermore, exposure to UV radiation may cause oxidation of double carbon links to produce color compounds that contain peroxide. ${ }^{13}$ Discoloration may also be of exogenous origin, mainly caused by the absorption of coloring solutions such as tea, coffee and mouth rinses. ${ }^{14}$

Pulp-protection materials are extremely important for pulp health, affecting protection against thermal, electric and mechanical stimuli. ${ }^{15}$ Nonetheless, depending on the cavity depth and the transparency of the restoration material, the color of the pulp-protection material may affect the end result of the esthetic restoration. At present, with the development of whitening techniques, teeth assume a lighter color and their restorations demand more translucent materials. Thus, protection materials can interfere in the final esthetic result of the restoration. ${ }^{16}$

The aim of this study was to asses, in vitro, the color stability of composites placed over calcium hydroxide and glass ionomer cement pulp protectors when submitted to an accelerated ar- tificial aging process. The hypothesis tested was that composites placed over protection materials present the greatest variations in color stability.

\section{MATERIALS AND METHODS}

For the development of this study, composites (Table 1) associated with two pulp-protection materials were used: Hydro C (Dentsply, Petrópolis, RJ, Brazil), a calcium hydroxide-based $(\mathrm{CH})$, and Vivaglass Liner (Ivoclar Vivadent, Schaan, Liechtenstein), a glass ionomer cement-based (GIC) material.

For each composite, 30 specimens were made in two layers, one with $0.5 \mathrm{~mm}$ of protection material and another with $2.5 \mathrm{~mm}$ of restoration material, with a total thickness of $3.0 \mathrm{~mm}$, placed on a $12 \mathrm{~mm}$-diameter Teflon matrix. To standardize the thickness of each layer, spacers were adapted over the central axis of the matrix within the thicknesses determined for each layer. After adapting the $0.5 \mathrm{~mm}$ spacer, the protection materials were manipulated according to the manufacturers' recommendations and inserted into the matrix until it was completely filled. After pressing, the 2.5 $\mathrm{mm}$ spacer was adapted over the central axis of the matrix and $1.0 \mathrm{~mm}$ and $1.5 \mathrm{~mm}$ increments of composite were applied and light cured with halogen light (Ultralux Electronic, Dabi Atlante, Ribeirão Preto, SP, Brazil, 400/500 nm, 350/500mW/ $\mathrm{cm}^{2}$ ) for the time recommended by the manufacturer. The intensity of the light source $\left(\mathrm{mW} / \mathrm{cm}^{2}\right)$ was measured periodically by a radiometer (Curing Radiometer Model 100, Demetron Research Corp., Danbury, CT, USA). A glass cover slip was placed over the last resin layer, to enable a flat surface to be obtained and to avoid oxygen inhibition. At the end of the light curing process, the samples were removed and stored in isolated receptacles in the absence of light at $37^{\circ} \mathrm{C}$ for 24 hours.

Specimens were polished with abrasive paper discs in a descending order of abrasiveness (SofLex, 3M ESPE, Sumaré, SP, Brazil), with alternating intermittent movements, and wetting the surface to avoid overheating. After this they were separated into 3 groups $(n=10)$, according to the type of protection used (Table 2).

The samples were submitted to the initial color reading against a white background block (Standard for $45^{\circ} 0^{\circ}$ Reflectance and Color Gardner 
Laboratory Inc. Bethesda, Maryland 20014) using a spectrophotometer (PCB 6807 Byk Gardner, Geretsried, Germanyl. The observation standard simulated by the equipment follows the CIE $L^{*} a^{*} b^{*}$ system, which consists of two axes, a* and $b^{*}$, which are at right angles and represent the dimension or color. The third axis, perpendicular to the $a^{*} b^{*}$ plane, is the lightness $L^{*} .{ }^{17}$ When it is activated, the spectrophotometer composed of 30 LED lamps of 10 different colors, disposed in a circular arrangement light up, with the light beam incident on the material surface at an angle of $45^{\circ}$ using the primary standard illuminant D65, which simulates the spectrum of natural daylight. This beam is reflected back to the appliance at $0^{\circ}$, and thus, it captures and records the values of $L^{*}$, $a^{*}$ and $b^{*}$ of each sample. The observer standard used was $10^{\circ}$. These were considered the initial values.

The samples were submitted to accelerated artificial aging (C-UV, Comexim Matérias Primas Ltda, São Paulo, SP, Brazil) under the action of UV light and condensed air-saturated water. The fixed working program consisted of 4 hours exposure to UV-B light at $50^{\circ} \mathrm{C}$ and 4 hours condensation at $50^{\circ} \mathrm{C}$ for a period of 384 hours, ${ }^{18}$ equivalent to 1 year of clinical service. ${ }^{19}$ According to Ruyter et a ${ }^{20}$ color alteration occur in the first 300 hours of the aging process. After this procedure, the specimens were submitted to second color reading, and the color variation $(\Delta E)$ was calculated by the following formula: $\Delta \mathrm{E}=\left[\left(\Delta \mathrm{L}^{*}\right)^{2}+\left(\Delta \mathrm{a}^{*}\right)^{2}+\left(\Delta \mathrm{b}^{*}\right)^{2}\right]^{1 / 2}$, where $\Delta \mathrm{L}=$ final $\mathrm{L}^{*}$ - initial $\mathrm{L}^{*} ; \Delta \mathrm{a}=$ final $\mathrm{a}^{*}$ - initial $a^{*}$ and $\Delta b=$ final $b^{*}$ - initial $b^{*}$. The KolgomorovSmirnov test was applied to test the normal distribution of the data and the values were submitted to statistical analysis (2-way ANOVA - Bonferroni, significance level at $95 \%$, factors of variation composite $\mathrm{x}$ protector material).

\section{RESULTS}

Figure 1 shows a comparison of the $L^{*}, a^{*}$ and $b^{*}$ values obtained before AAA for each group tested. Through the data analysis, it was detected that the samples placed on $\mathrm{CH}$ presented lower $L^{*}$ values than those placed on GIC (Figure 1), and were statistically significant $(P<.05)$ in comparison with the other groups for the QuixFil composite. Composites placed on GIC presented slightly lower $L^{*}$ values than those obtained for the Control
Group, without statistically significant differences ( $P>$.05). Furthermore, the protector exerted great influence on the $b^{*}$ coordinate (which varies from blue to yellow), especially for the Quixfil composite. Nevertheless, when the two studied composites were placed on GIC, both presented lower b* values than those of the $\mathrm{CH}$ group, which were statistically significant in comparison with the values of the other groups $(\mathrm{P}<.05)$.

The $\Delta \mathrm{E}$ measurements obtained for each studied group and their respective standard deviations are shown in Table 3. The data show that Concept was the material that presented the greatest $\Delta \mathrm{E}$ variation, in all groups, presenting statistically significant values when compared with Quixfil, Control and $\mathrm{CH}$ groups. When the behavior of Concept was compared with regard to the type of protection material used, high $\Delta \mathrm{E}$ values were found for control samples (without protection), with statistically significant results $(P<.05)$ in comparison with the protected groups that presented no differences between each other $(P>.05)$. The Quixfil composite did not present statistically significant differences $(P>05)$ with regard to the protection material for any of the studied groups.

When analyzing the results in Table 3 , it is found that the results of $\Delta E$ for the control group were higher than those for the groups with pulpprotection material, with statistically significant values for Concept $(P<.05)$.

\section{DISCUSSION}

The increasing esthetic requirements of the patients, allied to the technological development of esthetic restoration materials, have led to an increase in their use. Nonetheless, although they present good mechanical properties, professionals are concerned about the poor color stability of these materials; especially in the long term. ${ }^{20-22}$ Instrumental analyses with the aid of a spectrophotometer have allowed objective results to be obtained. This method combined with accelerated artificial aging has routinely been used to study the esthetic properties of restoration materials. ${ }^{23-30}$

Studies conducted under accelerated aging conditions allow one to predict the physical behavior of dental composites. Most polymers have functional groups in their molecular chains, which absorb ultraviolet light; among them are the carbonyl group $(\mathrm{C}=0)$, aromatic rings and double 
carbon links $(\mathrm{C}=\mathrm{C}) .{ }^{21}$ When a polymer molecule absorbs ultraviolet light through the functional groups, the energy leads to the structure being in a more unstable state. These groups can return to their original state in phases emitting the excess energy in a longer wavelength. If the excited molecule cannot disperse the excess energy by some means, there will be a rupture; that is, photochemical degradation. Degradation that occurs due to aging, such as the loss of color or shine, loss of opacity, loss of adherence and the appear-

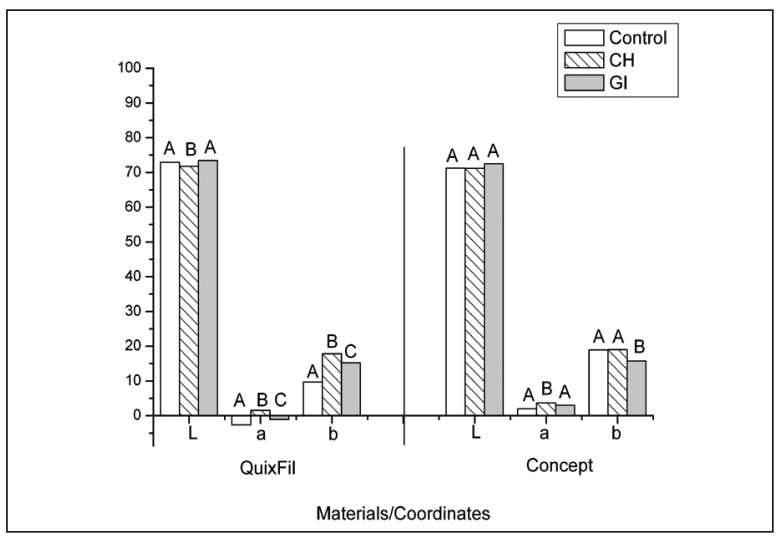

Figure 1. Clinical appearance of the same lesion. The overlying mucosa was normal and there was not any sign or symptom. ance of cracks is observed, and results from the action on the composite matrix in combination with the light-cure quality, method and light-cure time. ${ }^{12,21}$ Moreover, AAA leads to the degradation of the matrix/silane/filler, since the composite absorbs the water that penetrates through the filler/resin interface, which leads to hydrolysis of the silane, reducing the retention of the filler particles. $^{31}$

Reference values established whether or not there was difference in color before aging, and demonstrated that the presence and type of protection material would alter the appearance of the restoration material. The $L^{*}$ axis reveals the amount of white there is in the color, so, the more white there is in the color, the greater is the $L^{*}$ value. Thus, it was seen that the test specimens placed on glass ionomer cement were more luminous than those placed on calcium hydroxide, since glass ionomer is a white material when compared with calcium hydroxide, which has a darkyellow color (Figure 1) and the final restoration would reflect less light, which gives a lower mean $L^{*}$ value. As regards the $b^{*}$ coordinate, the greater

Table 1. Composites used in the study.

\begin{tabular}{l|c|c|c|c}
\hline Composite & Color & Mean particle size & Particle percentage (in weight) & Manufacturer \\
\hline QuiXfil & Universal & $1-10 \mu \mathrm{m}$ & $86 \%$ & $\begin{array}{c}\text { Dentsply DeTrey (Konstanz, } \\
\text { Germany) }\end{array}$ \\
Concept & B2 & $0.4 \mu \mathrm{m}$ & $77.50 \%$ & $\begin{array}{c}\text { Vigodent (Rio de Janeiro, RJ, } \\
\text { Brazil) }\end{array}$ \\
\hline
\end{tabular}

Table 2. Studied groups.

\begin{tabular}{lcc}
\hline Groups & Material & Pulp-protection material \\
\hline Control & & Without protection (control) \\
$\mathrm{CH}$ & Quixfil & Calcium hydroxide \\
$\mathrm{GIC}$ & & Glass ionomer cement \\
$\mathrm{Control}$ & & Without protection (control) \\
$\mathrm{CH}$ & Concept & Calcium hydroxide \\
$\mathrm{GIC}$ & & Glass ionomer cement \\
\hline
\end{tabular}

Table 3. Comparison of means (standard deviation) of $\Delta \mathrm{E}$ (2-way ANOVA - Bonferroni - 95\%).

\begin{tabular}{lccc}
\hline Composite & Control & CH & GIC \\
\hline Quixfil & $4.49(0.9) \mathrm{a}, \mathrm{A}$ & $2.91(1.2) \mathrm{a}, \mathrm{A}$ & $3.89(1.8) \mathrm{a}, \mathrm{A}$ \\
Concept & $14.11(1.4) \mathrm{a}, \mathrm{B}$ & $9.38(3.6) \mathrm{b}, \mathrm{B}$ & $7.04(4.5) \mathrm{b}, \mathrm{A}$ \\
\hline
\end{tabular}

* Different letters, lower case in the line and upper case in the column, indicate statistically significant results $(P<.05)$. 
its value is, the closer the color of the material is to yellow. All the alterations in the coordinates of the CIE Lab scale will reflect on the $\Delta E$ (Delta E) values. Consequently, the data confirm the hypothesis that pulp-protection materials directly interfere in the restoration color even before they are submitted to accelerated artificial aging.

The $\Delta \mathrm{E}$ analysis allows the assessment of material-color stability. Therefore, higher $\Delta \mathrm{E}$ values, result in greater color variation. Concept presented the greatest color variation (Table 3). The size and volume percentage of inorganic particles could be factors that influence $\triangle E$ after $A A A_{;}{ }^{31}$ a microhybrid composite could be more transparent than hybrid composites after the surface degradation, so that the pulp protector was more visible. With a high percentage of inorganic filler in Quixfil there would be more light reflected inside the material, resulting in lower transparency. ${ }^{32}$ The same phenomenon occurred in the samples without protection. Both composites presented higher $\Delta \mathrm{E}$ values in comparison with the samples with pulp-protection material. The difference in light transmittance of the dental resin composites affected their clinical appearance. ${ }^{33}$ When light is illuminated on a translucent specimen backed by a glossy/white background, many fractions of light reaching the background may be reflected. However, when backed by a matt/black background or a light trap, the degree of reflection may be significantly reduced. ${ }^{34,35}$ With the absence of the protective material, the samples could present greater translucence, without the opacity of the protective material, providing greater light reflection through the material.

There was no significant difference between the composites placed on GIC (Table 3), despite the high $\Delta \mathrm{E}$ values for Concept. According Ruyter et a ${ }^{20}$ Concept and Quixfil presented clinically unacceptable variations ( $\triangle E \geq 3.3)$ in the control group (14.1 and 4.5, respectively). In the other groups only Quixfil placed on $\mathrm{CH}$ was within the clinical parameters. The results proved the hypothesis that the pulp-protection materials interfere directly in the color of the restoration material and that the behavior of the composites differs over the course of time, according to the type of composite studied.

\section{CONCLUSIONS}

According to the methodology used and the results obtained in this study, it could be concluded that:

- Pulp-protection material affected the original color of the composite before and after accelerated artificial aging;

- The effect of accelerated artificial aging differs, depending on the type of composite used (hybrid or microhybrid);

- Only Quixfil placed on $\mathrm{CH}$ was within acceptable clinical parameters $(\triangle \mathrm{E}<3.3)$.

\section{REFERENCES}

1. Qvist V, Thylstrup A, Mjor IA. Restorative treatment pattern and longevity of amalgam restorations in Denmark. Acta Odontol Scand 1986;44:351-356.

2. Dijken JW. A clinical evaluation of anterior conventional, microfiller, and hybrid composite resin filings: A 6-year follow-up study. Acta Odontol Scand 1986;44:357-367.

3. Roberts MW, Folio J, Moffa JP, Guckes AD. Clinical evaluation of composite resin system with a dentin bonding agent for restoration of permanent posterior teeth: A 3-year study. J Prosthet Dent 1992;67:301-306.

4. Redman CD, Hemmings KW, Good JA. The survival and clinical performance of resin-based composite restorations used to treat localized anterior tooth wear. Braz Dent J 2003; 194:566-572

5. Hosoya Y, Goto G. Color changes of light-cured composite resins. J Clin Pediatr Dent 1992;16:247-252.

6. Dietschi D, Campanile G, Holz J, Meyer JM. Comparison of the color stability of ten new-generation composites: an in vitro study. Dent Mater 1994;10:353-362.

7. Inokoshi S, Burrow MF, Kataumi M, Yamada T, Takatsu T. Opacity and color changes of tooth-colored restorative materials. Oper Dent 1996;21:73-80.

8. Fruits $T$, Duncanson M, Miranda F. In vitro weathering of selected direct esthetic restorative materials. Quintessence Int 1997;28:409-414.

9. Buchalla W, Attin T, Hilgers R, Hellwig E. The effect of water storage and light exposure on the color and translucency of a hybrid and a microfilled composite. $J$ Prosthet Dent 2002;87:264-270.

10. Pires-de-Souza FCP, Garcia LFR, Hamida HM, Assirati LC. Color stability of composites subjected to accelerated aging after curing using either a halogen or a light emitting diode source. Braz Dent J 2007;18:119-123. 
11. Janda R, Roulet JF, Kaminsky M, Steffin G, Latta M. Color stability of resin matrix restorative materials as a function of the method of light activation. Eur J Oral Sci 2004; 112:280-285.

12. Janda R, Roulet JF, Latta M, Steffin G, Ruttermann S. Color stability of resin-based filling materials after aging when cured with plasma or halogen light. Eur J Oral Sci 2005; 113:251-257.

13. Ferracane JL, Moser JB, Greener EH. Ultraviolet light-induced yellowing of dental restorative resins. J Prosthet Dent 1985;54:483-487.

14. Celik C, Yuzugullu B, Erkut S, Yamanel K. Effects of mouth rinses on color stability of resin composites. Eur J Dent 2008;2:247-304

15. Fava LR, Saunders WP. Calcium hydroxide paste: classification and clinical indications. Int Endod J 1999;32:257-253.

16. Kwon YH, Huo MS, Kim KH, Kim SK, Kim YJ. Effects of hydrogen peroxide on the light reflectance and morphology of bovine enamel. J Oral Rehab 2002;29:473-477.

17. CIE - Commission Internationale De L'eclairage. Colorimetry technical report. Vienna, Austria: Bureau Central da La CIE. 2nd ed. pub. n¹5; 1986.

18. ASTM Standards G154-00a. Standard practice for operating fluorescent light apparatus for UV exposure of nonmetallic materials. Pennsylvania, United States: Annual Book of ASTM Standards v. 14.04; 2006.

19. Heydecke G, Zhang F, Razzoog ME. In vitro color stability of double-layer veneers after accelerated aging. $J$ Prosthet Dent 2001;85:551-557.

20. Ruyter IE, Nilner K, Moller B. Color stability of dental resin materials for crown and bridge veneers. Dent Mater 1987;3:246-251.

21. Kolbeck C, Rosentritt M, Lang R, Handel G. Discoloration of facing and restorative composites by UV-irradiation and staining food. Dent Mater 2006;22:63-68.

22. Paravina RD, Kimura M, Powers JM. Evaluation of polymerization-dependent changes in color and translucency of resin composites using two formulae. Odontology 2005;93:46-51.

23. Rosentritt M, Esch J, Behr M, Leibrock A, Handel G. In vivo color stability of resin composite veneers and acrylic resin teeth in removable partial dentures. Quintessence Int 1998;29:517-522.

24. Shintani H, Yamaki M, Inoue T. Analysis of camphorquinone in visible light-cured composite resins. Dent Mater 1985; 1:124-126.

25. Powers JM, Fan PL, Raptis CN. Color stability of new composite restorative materials under accelerated aging. $J$ Dent Res 1980;59:2071-2074.
26. Asmussen E. Factors affecting the color stability of restorative resins. Acta Odontol Scand 1980;41:11-18.

27. Burrow MF, Makinson OF. Color change in light-cured resins exposed to daylight. Quintessence Int 1991;22:447-452.

28. Davis BA, Friedl KH, Powers JM. Color stability of hybrid ionomers after accelerated aging. J Prosthodont 1995;4:111115.

29. Zanin FR, Garcia LFR, Casemiro LA, Pires-de-Souza FCP. Effect of artificial accelerated aging on color stability and surface roughness of indirect composites. Eur J Prosthodont Restor Dent 2008;16:10-14.

30. Pires-de-Souza FCP, Casemiro LA, Garcia LFR, Cruvinel DR. Color stability of dental ceramics submitted to artificial accelerated aging after repeated firings. $J$ Prosthet Dent 2009;101:13-18

31. Ferracane JL. Hygroscopic and hydrolytic effects in dental polymer networks. Dent Mater 2006;22:211-222.

32. Lee YK, Lu H, Powers JM. Effect of surface sealant and staining on the fluorescence of resin composites. J Prosthet Dent 2005;93:260-266.

33. Arikawa H, Fujii K, Kanie T, Inoue K. Light transmittance characteristics of light-cured composite resins. Dent Mater 1998; 14:405-411.

34. Lee YK, Lim BS, Kim CW. Effect of surface conditions on the color of dental resin composites. J Biomed Mater Res Appl Biomater 2002;63:657-663.

35. Lee YK, Lim BS, Kim CW. Difference in the colour and colour change of dental resin composites by the background. J Oral Rehabil 2005;32:227-233. 